\title{
Potential and Observed Environmental Impacts of the COVID-19 Pandemic
}

\author{
Vaishnavi Gore ${ }^{1}$, Dr.Swarupa Chakole ${ }^{2}$ \\ ${ }^{1}$ Medical intern, Department of CommunityMedicine, Jawaharlal Nehru Medical College, DattaMegheInstitute \\ Of Medical Sciences (Deemed to be University), Wardha, Maharashtra, India. \\ ${ }^{2}$ Professor, Department of CommunityMedicine Jawaharlal Nehru Medical College, DattaMegheInstitute Of \\ Medical Sciences (Deemed to be University), Wardha, Maharashtra, India. \\ Email: vaishnavigore29@gmail.com
}

Review article

Conflict of interest: None

\begin{abstract}
:
Many ecological variants have impact on the onset and communicability of infectious diseases or pandemics, which may in later days can trigger environmental feedback. The most potentially lethal virus of this century coronavirus disease (COVID-19) was declared an epidemic on March 13, 2020, and its vigorous spread, congruous coverage and its many diverse and complicated after effects may have made it a very dangerous disease to counteract the problems related to it in such a short time period making it once in only century disaster around the world. Most of the countries around the world being currently in a situation of chaos and suffering of this disease and its consequences have responded with great concern and measures by taking social distancing methods and measures of various kinds and drastically reducing the spread of the virus and helping in prevention by it have also helped in resolving many economic and other activities of the country to cope with. As a result, the COVID-19 pandemic at the end of April 2020 caused many environmental impacts, including positive impacts such as improved air quality. Negative impacts such as coastal pollution through the elimination of water and sanitation supplies in urban areas and in rural have shown it effects of healing the surrounding which was caused by the halting to many industries and the release of waste products and hampering of the transport and its emission after the public went into home isolation after the pandemic started. This study provides a first overview of the observed environmental and possible aftermath of COVID-19. We argue that the impact of COVID-19 is largely determined by anthropogenic factors that become apparent as public events declines around the globe, and effects on towns and human health will continue to exist.
\end{abstract}

Keywords: COVID-19, SARS-CoV-2, global climate, epidemic, weather, imperishable.

\section{INTRODUCTION}

This planet is a actively developing system that is constantly being molded with interconnection to surroundings. Fluctuations with difference is a non-linear and variable factor like Earth, but once a threshold is crossed, the stability of the system can be pushed into a new regime, with important consequences on various conceptual and secular values. Inference and anticipating the effects of exaggerated switch of problems not only of studies, involving economic, civil and biological, also for our community. Exaggerated fluctuations in original methods and events, often amplified or caused by human activity, can pose risks to communities and the environment and lead to disasters. The idea of calamity has developed, but now the definition of the Intergovernmental Panel on Climate Change (IPCC): a catastrophe is a serious disruption in the working of a society due to harmful physical, biological or human influences, resulting in widespread disruption at different levels and in different systems (environmental, economic and social). It is an event that has negative effects. The recovery process requires an emergency response, including external support. Although calamity is known as severe conditions, they can also become persistent. Most studies today consider communal difference an 
important aspect of disasters. Inspite of the fact that calamities often became aware of its sudden situations, which may turn into a chronic case. Various studies today consider community disturbance an important factor or necessary aspect of disasters. The conceptual area of the sudden impact is many a time relevant to the material features of the difficulty, but the prolonged impact may be broader varying on the active similarities of the impacted region area. Just like, earth tremors can lead to immediate harm and victims in the region of effect, but the negative effects on public health, the surrounding, ancestral monuments and wealth activities can affect an area and last for years.

A pandemic is the risk associated with the outbreak of a major infectious disease that can lead to a significant increase in morbidity and mortality over a large geographical area and cause significant economic, social and political disruption. A pandemic can be described as a disaster because of its global impact on the population and the expected long-term effects and socio-environmental consequences. On March 13, 2020, the World Health Organization (WHO) announced that a new coronavirus disease (COVID-19), which is plunging humanity into a permanent global crisis, has been declared a pandemic. The COVID-19 pandemic has an obvious impact on many aspects of the environment and poses significant challenges to a variety of socioecological systems. Due to the severe acute respiratory syndrome Coronavirus 2 (SARS-CoV-2), COVID-19 has infected approximately more than 200 nations and regions in more than four different $\mathrm{WHO}$ areas and about three world wide transports by April 29, 2020.SARS-CoV-2 appears to have high mortality rates and health system failures in the areas of public wellbeing, knowledge, public health practices and health care delivery. Given the obvious impact of planetary factors, there are growing problems and inference regarding to the switch of effects of the COVID-19 pandemic.

Significant progress has been made in the areas of technology, medicine, environment and biodiversity conservation, resulting in a global The quality of life has improved in several ways. Inspite this specific development in way of life, various predictable hazardous events dominate the world wide plan, including the growing threat of terrorist organizations, weather and surroundings change, atomic procreation, wealth crisis and the decline of elective government. In this circumstances, the flexibility of towns to widespread catastrophe is a not very well put together.

Following the introduction [1] the paper is divided into five sections: [2]Methods; [3] COVID-19 and other 21st century pandemics; [4] Environmental impacts, physical and ecological systems, global environmental issues, environmental monitoring and climate services; [5] Current and further weather impacts; and [6] Conclusions. Important points of observed effects on urban and health of community is included in various divisions.

\section{Procedure}

One of the many methodological difficulty of this very article was to gather relevant knowledge about the surrounding influence of the COVID 19 widespread within a very short time frame. During the pandemic, a wealth of information was available from a variety of sources. Because of rapid development of time to the event, sources from various publications was also added in this research, but only when they reported on or referred to the view of verified consultants. Wherever possible, several validation rounds were conducted. [7]

Particularly remarkable is the wealth of information that is accessible in a early 
period of time, that shows a great attraction in this article. The current study was based on about a 100 references (i.e. 54 blogs, two journals, two chapters, 73 peer-reviewed articles and 11 reports) and 115 sites, we also accept that we have used about twice as many sources of information.

The evidence collected consisted of details, knowledge, study, views and research issued by the progression of COVID 19 and was specified, as shown in the following sections of this study, for its clear focus on environmental, urban and public health issues.[8]

\section{COVID-19 and such deadly diseases}

The important factors leading to widespread and epidemics is the close interconnection in between public habitat and domestic and wild organisms. Many organisms go through jungles and invade the public habitat by trapping prey and utilizing of wildlife, wildlife trade and other wildlife contacts. Urban areas are particularly at risk because of their increasing number and migration.[9]

COVID-19 exceeds major epidemics of the this century past in matters of conceptual range and social impact and the one disease whose extensive and complex environmental effects Another important epidemiological feature of the 21 st century is the fact that COVID-19 is one of the disease with a huge impact on surroundings.

a) In 2003, Severe Acute Respiratory Syndrome (SARS) occurred, causing probably a few more or about 8000 contaminations of humans with a death rate of about $10 \%$ and with a limited impact on the general and local economy. The outbreak stopped suddenly in the month of July 2003 and since then very few cases of SARS coronavirus have been identified in humans. Not. b) The H1N1 (swine flu) 2009 organism caused the first widespread disease to occur in Mexico and the United States in the month of March and of April 2009. Global migration and air travel made it a global pandemic with an estimated mortality rate of $0.4 \%$.

c) The Ebola virus was earliest identified in Zaire in 1976. When the virus was earlier identified, more than 20 familiar eruptions of Ebola was first caught in subSaharan Africa, mainly in Sudan, Uganda, the Democratic Republic of Congo, and Gabon. Currently, there is no cure or effective curative treatment system against this deadly virus. Even though this lethal virus has a significant spread and hazardous capacity (due to its easy world wide spread), as this very sporadic Ebola epidemic in West Africa has shown, which resulted in about 28,000 confirmed cases and 11,000 deaths , Ebola has a limited geographical scope.

d) Zika fever (2015-2016) was earliest detected in 1947 in the Zika forest in Uganda by a feverish rhesus monkey. Since 1954, when the first human case was found, the Zika virus has remained a specific and spread of infection in Africa and Asia. Though, by 2015, an estimated 440,000 to 1.3 million cases are expected to have advanced from Brazil to 29 states in the United States Of Americas , and in the month of November 2016, the WHO declared the termination of the Zika epidemic.[10]

In local, temperate, wet, airy and condensation can promote the communicability or suppression of epidemics. Though, few researches have 
shown that general climate changes (cooler temperatures, milder time of day and lower humidity) can promote spread, other researchers have found no proof that hotter climate is a determining factor in reducing Covid-19 cases. Increased UV radiation, especially during the warmer weather, leads to deactivation of corona viruses, and extensive analysis on this topic suggests that global warming is not hampering its spread of this pandemic.[11,12]

Given this fact that corona viruses tend to spread in the cold seasons (i.e. through out periods of less sunshine) in winter, drier conditions, this is a very shocking revelation that Italy was one of the very few countries in Europe to be badly impacted by a world wide disease and that its health services were immediately overloaded. Northern Italy went through the driest days and a moderately cold winter due to a strong arctic vortex; the winter 2019-2020 was one of the driest winters in the last 60 years. The effect of the social and wealth systems of the nation suddenly raised worrisome news of the or about the very possible spreading routes of the disease and its transmission in Europe.

\section{Impacts on the Environment}

Since the beginning of the crisis, the environmental impact of the COVID-19 pandemic has been brought into focus by (a) monitoring and analyzing the rapid and known changes. While factorial presumptions have taken precedence, persistent subjective studies should await pertinent source and various evidence; most aspects of the habitat influence of the COVID- 19 pandemic were not a direct consequence of the virus itself. The restrictions and sudden closures of sectors such as heavy industry, transportation and host country companies had a direct impact on the habitat.[13]

Moreover, a socio-environmental effect of the VIDOC 19 sporadic disease could range from fundamental switches of the personal well being in daily routine with interaction to the nature and its surrounding with the transport and various other means of lifestyles, society and international affairs to those that merely allow for faster changes than would normally be the case in common public point of view but can be a major advance if seen as a whole problem to the cause of its effects and realizing the many other ways we can deal with the very systems with which we can deal with then current problems at the very best of the roots of it and can lead to better understanding of the future for which we work and can lead a sustainable life which was and always be the dream of the protagonist. From a very narrow point of view, a world wide disease could lead to a more reliable future, involving increased socio-ecological flexibility and lesser resource, what can be considered as a advancement to the greater cause for humanity.[14]

The secular intension of coronavirus effects varies from rapid (days to weeks), immediate (months) and delayed (years), providing a matrix of different examples (Figure 2). The initial effects are segregated into immediate habitat changes, such as the quality of town air and water, and episodes of pollution, such as sanitary sewage, while the rapid and delayed term effects are mainly assessed as productive. 
Article Received: 16th October, 2020; Article Revised: 30th December, 2020; Article Accepted: 08th January, 2021

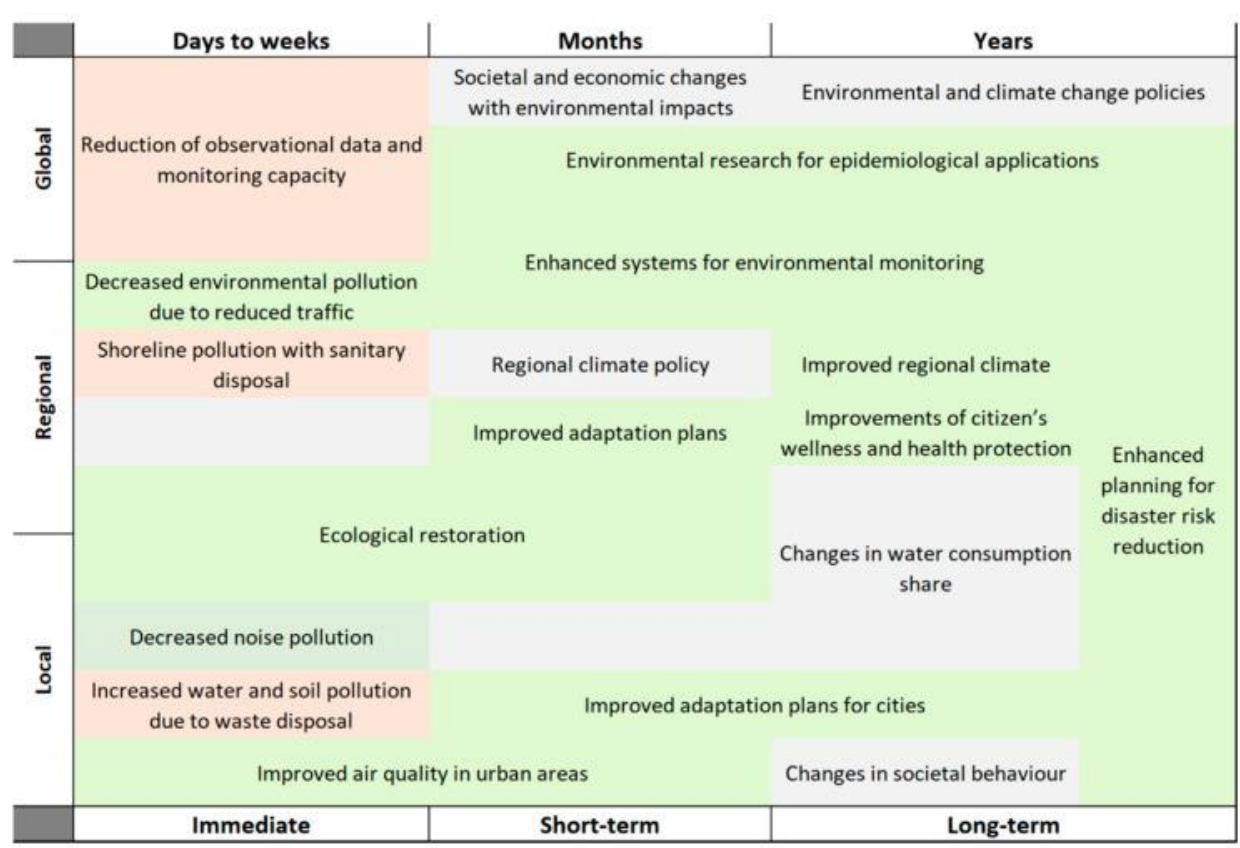

\subsection{Air Quality and Local Climate}

Space station distant imaging gives actual proof of the positive effects of the COVID 19 disease on wind quality.[15] For example, NASA and the pollution monitoring satellites of the European
Space Agency (ESA) measured a remarkable reduction in nitrogen dioxide (NO2) in northeastern China during the recession in January-February 2020 (Figure 


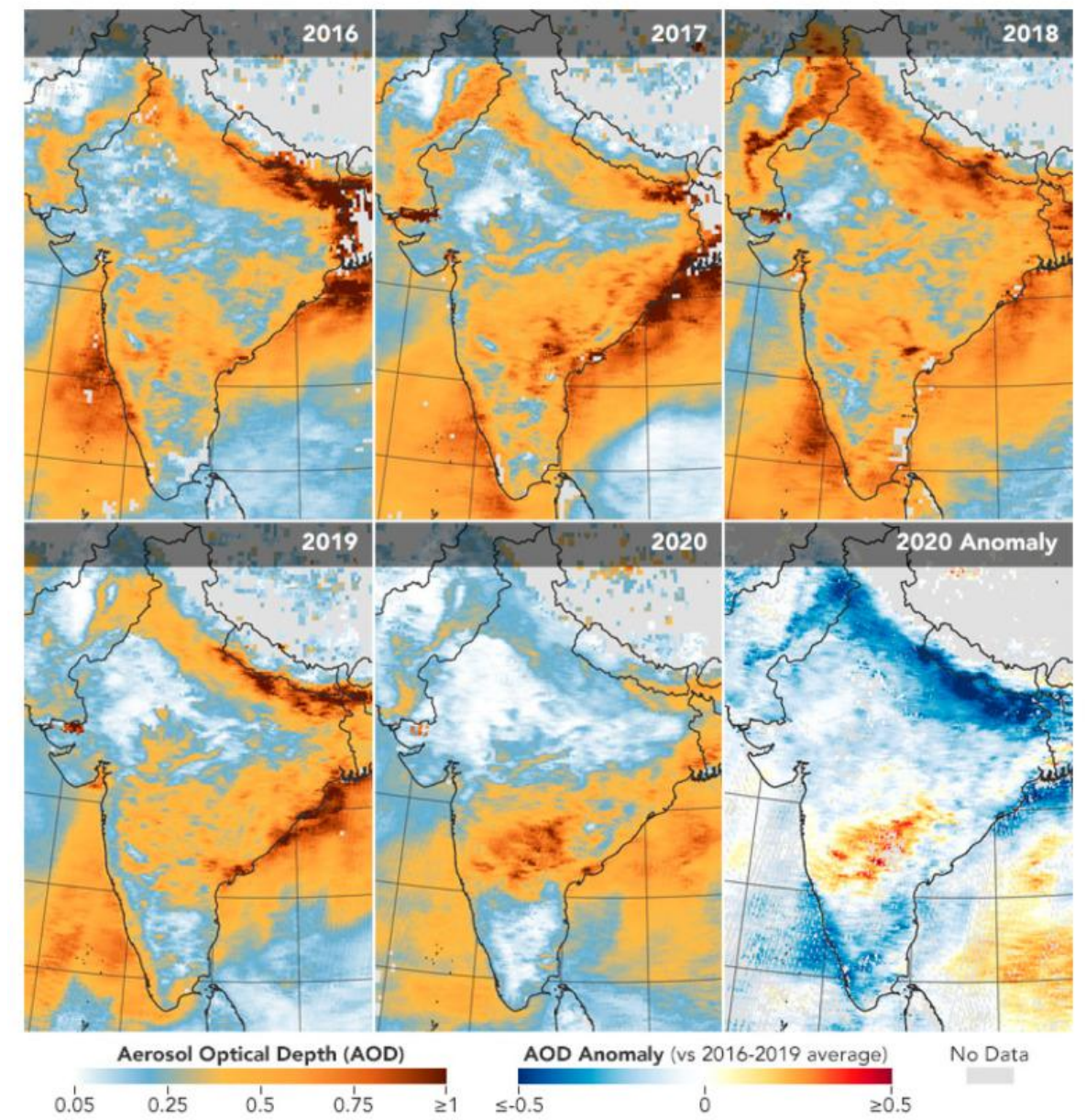

4.2.Marine life and hydration source Although the rapid changes of the COVID 19 disease on water bodies and clean hydration assets is very meek, water bodies and hydration assets could be grandiose on a quarterly or yearly basis.[16] Because of reduced ship congestion and travelers events, the waters of Venice were emptied when the city was closed in March and April 2020 due to the corona virus . 


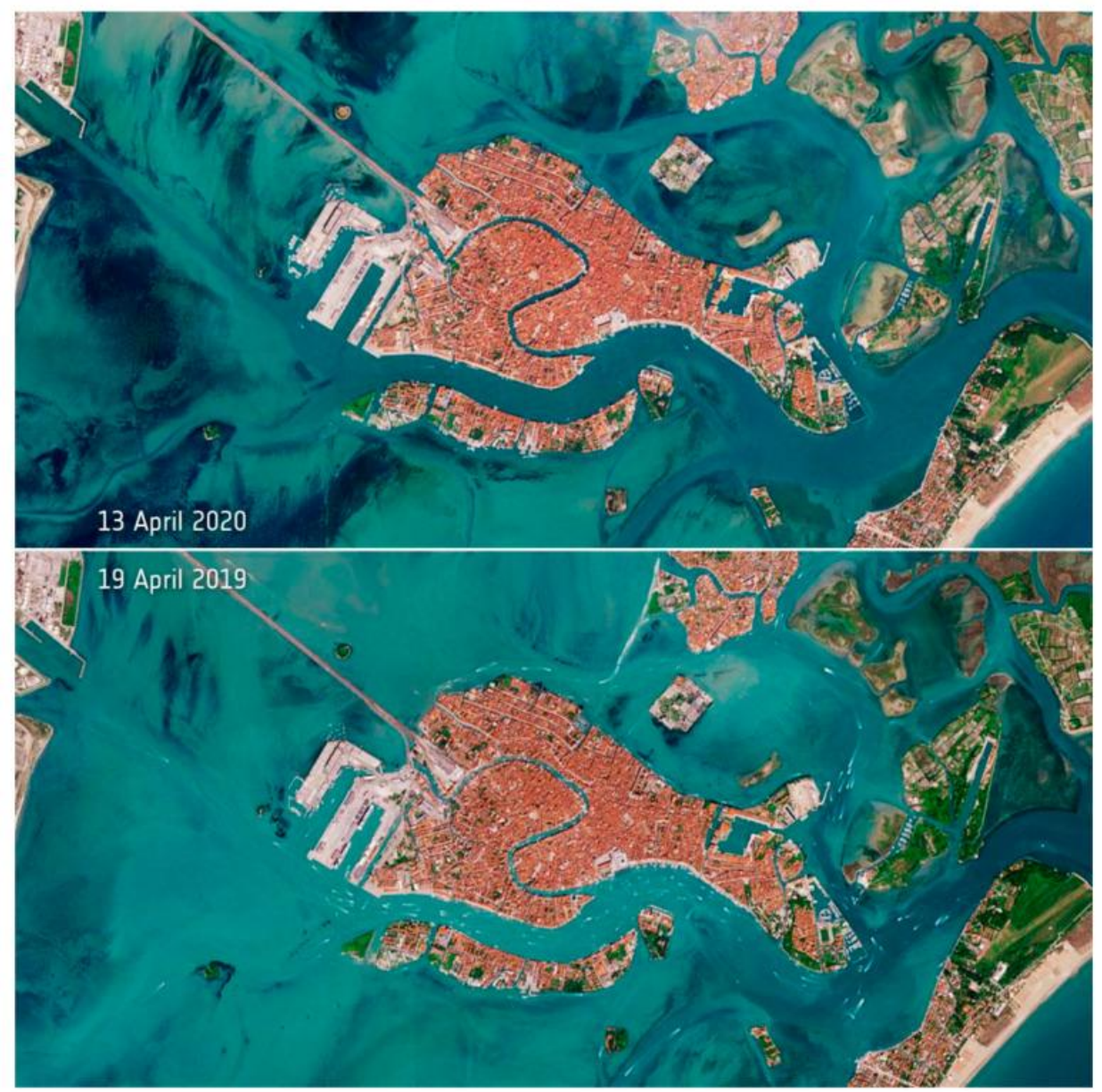

5. Effects of current weather and its impact Disease spread through public movements in the relation to weather switch has gained scientific awareness even before the present pandemic.[17]

An investigation of the correlation in the weather and coronaviruses concentrates on more than one questions. (a) what the climate modulates in expanse of the virus and sustainability of the disease, and (b) the very expanse till which the viral disease affects profitable strategies or policies that are got hold to counterbalance the effects of weather. The initial point is essentially well organized in nature and relates primarily to a field of atmosphere and epidemiology. The next one is further complex because profit, ministerial and communal energetic influence the process of changing the world view.

The analysis of the straight effects of pandemics on weather is more complex.
This is because projections must not only solve the dynamics of infection, but also take into account the wealth, civil and social view of the spread of the infection.[18]

The straight impact of weather change are likely to be due primarily to the global slowdown in production and transport activities. At this point in time, it is not easy to determine the worldwide impact. For sample, release in China, which has the prolonged shutdown time, have fallen by 25 percent, which corresponds with the reduction of around more than 150 million tons of $\mathrm{CO} 2$ in February alone. Nonetheless, probability of a worldwide decrease in $\mathrm{CO} 2$ release is estimated about $5 \%$ globally, and Scripps Research Institute has published a "Representative Concentration Path (RCP)" (Representative Concentration Path) for 
climate change scenarios6 that suggest

trends in emissions .
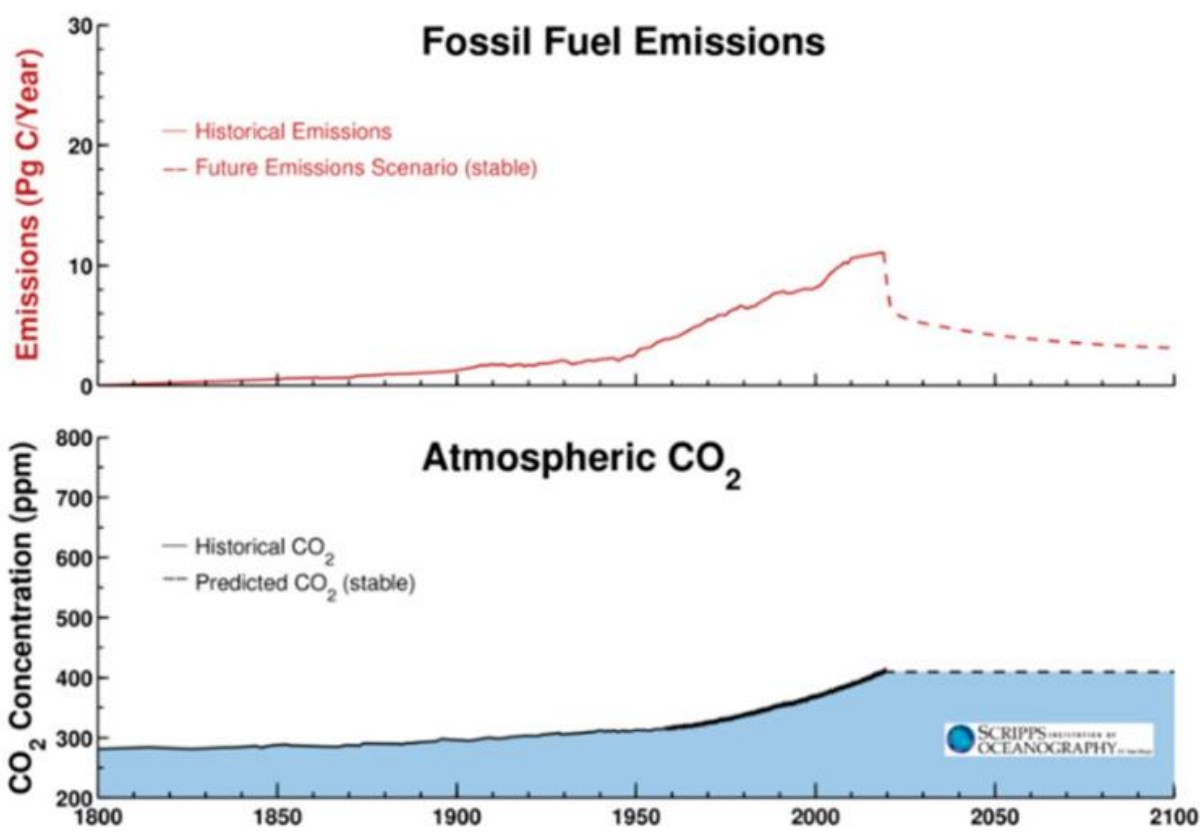

This prediction leads to fundamental speculation about the indirect effects of corona viruses on the global climate. We note the rapid increase in $\mathrm{CO} 2$ emissions after the economic crisis of 2008-2009, which suggests that a similar response to this pandemic will follow.

According to experts, the disappearance of the pandemic will lead to one of the two most divergent paths. On the one hand, some believe that coronaviruses can help develop the infrastructure of government, science and industry to address environmental problems such as weather switch. Though coronaviruses and weather switch work on various periods scales, they show a familiar phenomenon in view of the development and effect of questions. Sessions can thus be learned for environmental protection from the lessons learned from pandemics. For example, recovery from a pandemic has the potential to divert attention from habitat problems.[19]

Indeed, it has been switched: COVID-19 has eroded the fundamental principles of worldwide production. Corporates should rethink the different-tiered, transnational contributions that control the manufacture and creator of by-products. There are also profound changes ahead, and individuals must rethink their life choices.[20]

The COVID 19 pandemic has had an unmatched impact on the environment in view of conceptual area, twist and singularity. For the earliest possibility, the consumption of the town collection of more than a billion people in Europe has practically come to a standstill in terms of mobility, transport and profit. The communal and profit way's taken to accommodate the disease have had community, topical and worldwide effects ranging from rapid to prolonged. A complete assessment of the impact is not feasible in the case of a disaster of enormous scale and complexity that is currently underway, and this book promises further research in several directions.

The COVID 19 pandemic clearly shows that public health and global wellbeing are inextricably linked, and clearly underlines the part of a multidisciplinary approach to finding solutions, and the role of a multidisciplinary approach to finding 
solutions, and this disaster is only a few weeks away (i.e. February-March 2020) Humanity was not yet ready for a global event, despite the fact that there were six other pandemics in the 21st century. Most countries have introduced strict restrictions on economic and social activities, with many direct physical and environmental impacts. Long-term effects are also expected, and a systematic point of view is needed to hold up avoidance, untimely notice of caution and various familiar impact of environmental deterioration [2123]. A number of reviews reflected on impact of Covid pandemic on various aspects of health and humans [24-27].

Certain new technological advances are of great value in controlling the spread of corona viruses in the environment, and various specific and comprehensive observation would facilitate the grouping of various similar knowledge. The rapid development of this catastrophe makes it clear that observation of the communeenvironmental situation is critical for early interference in order to restrict the lamina of the disease and the risk of a spread. According to resource, improved observation of the migration routes and volumes of migrants could have prepared territory to contain the proliferation of new coronaviruses. Facts, device and experience would be a major improvement in preparing for a possible future pandemic.

\section{CONCLUSIONS:}

This worldwide problem decisively demonstrates the calamity study and its research, weather consultation and environmental provision and the need to rethink the very system the use to deal with the crisis and unsegregated advancement in the face of the such events that are very unlikely to occur in any circumstances to this very nature of work. Ultimately, the COVID-19 sporadic disease will lead to significant switches in civil and profit behavior at the global level, and the very research on its base concentrates on the surrounding aspects of the effects arising with the progressing disease.

\section{REFERENCES:}

[1] Johnston A.S., Boyd R.J., Watson J.W., Paul A., Evans L.C., Gardner E., Boult V. Predicting population responses to environmental change from individual-level mechanisms: towards a standardized mechanistic approach. R. Soc. B. 2019;286:20191916. doi. 10.1098/rspb.2019.1916.

[2] Cremades R., Mitter H., Tudose N.C., Sanchez-Plaza A., Graves A., Broekman A., Bender S., Giupponi C., Koundouri P., Bahri M., et al. Total Thor. ca. 2019; 693:133662. doi.

10.1016/j.scitotenv.2019.133662.

[3] Field C.B., Barros V., Stocker T.F., Dahe Q. Managing the risks of extreme events and disasters to promote adaptation to climate change: a special report of the Intergovernmental Panel on Climate Change Cambridge University Press; Cambridge, UK: 2012 [Google Scholar].

[4] Zibulewsky J. Defining disasters: an emergency service perspective. Volume 14 Taylor \& Francis; Oxfordshire, Great Britain: 2001, pp. 144-149

[5] Fifth edition of Perry's Handbook of Disaster Research. Springer; Berlin/Heidelberg, Germany: 2018. Defining disasters: an evolving concept; S. 3-22.

[6] Ripoll Gallardo A., Pacelli B., Alesina M., Cerrone D., Iactone G., Faggiano F., Della Corte F., Alara E., ripoll Gallardo A., Pacelli B., Alesina M., Cerrone D., Iactone G., 
Faggiano F. Della Corte F. Mediumand long-term health impacts of earthquakes in high-income countries A systematic review and metaanalysis. Int. J. Epidemiol. 2018;47:1317-1332. 10.1093/ije/dyyy130.

[7] Disease management priorities: improving health and reducing poverty. Third edition: the International Bank for Reconstruction and Development; Washington, DC: The World Bank; Washington, DC: The 2017 Pandemic. Risks, impacts and mitigation.

[8] Cucinotta D., Vanelli M. WHO declares COVID-19 a pandemic Acta Bio-MedicaAteneiParm.

2020;91:157-160. 10.23750/adm.v91i1.9397.

[9] Opening Remarks of the WHO Director-General at the Press Conference on VIDOC, 19-30 March 2020 (accessed 11 May 2020); online at

https://www.who.int/dg/speeches/det ail/who-director-general-s- (openingremarks-at-the-media-briefing-oncovid-19---30-march-2020) available at.

[10] Coronavirus [(accessed 11 May 2020)]; available online: https://www.who.int/emergencies/dis eases/novel-coronavirus-2019.

[11] Ferretti L., Wymant C., Kendall M., Zhao L., Nurtay A., Abeler-Dörner L., Parker M., Bonsall D., Fraser C. Quantification of SARS CoV-2 transmission as the epidemic is controlled by digital contact tracking indicates that. Science. 2020; 368 doi. 10.1126/Wissenschaft.abb6936

[12] United Nations Development Programme - Human Development Indicators and Indicators: statistical update team 2018 (accessed 11 May 2020);

http://hdr.undp.org/sites/default/files/ 2018_human_development_statistica 1_update .pdf.

[13] Cornwall W. Can you price the Cornwall W. COVID19 option? Experts weigh life and economics The science. 2020;10doi. 10.1126/Wissenschaft.abb9969.

[14] Erdmann G. Transition from Democracy: The Loss of the Quality of Democracy, Hybridization and Collapse; GIGA Working Paper; Berlin, Germany: 6 April 2011 GIGA Working Paper No. 161.

[15] Hirst W., Phelps E.A., Buckner R.L., Budson A.E., Cuc A., Gabrieli J.D., Johnson M.K., Lustig C., Lyle K.B., Mather M., Long-term memory of the September 11 terrorist attacks: flash memory, events Memory, and factors affecting those memories. j. Exp. Psychol. Gen. 2009;138:161. 10.1037/a0015527.

[16] ilardi G.J. The September 11 attacks - a study on intelligence and counterintelligence operations of alQaeda. student. conflict. Fear. 2009;32:171-187. doi: $10.1080 / 10576100802670803$.

[17] The deterioration of the democratic political culture: the consequences of the perception of inequality ZeitschriftfürGerechtigkeitsstudien 2013; 26:471-491

[18] McCoy J. Tahminah Rahman, Murat Sommer Polarization and the global crisis of democracy: common patterns, dynamics and harmful consequences for democratic politics. am. behavior. sci. 2018; 62:16-42. doi: 10.1177/0002764218759576.

[19] Nicola M., Alsafi Z., Sohrabi C., Kerwan A., Al-Jabir A., Iosifidis C., Agha M., Agha R. Socioeconomic impact of coronaviruses and the COVID 19 pandemic: a review. Int J. Surg. 2020;78:185-193. doi: 10.1016/j.ijsu.2020.04.018.

[20] Scouras J. Nuclear war as a global disaster risk. j. Cost-benefit analysis. 
2019;10:274-295.

doi: 10.1017/bca.2019.16.

[21] Budhrani, A.B. "A Review: Coronavirus, Its Types, and Impact of Covid-19 on Global Wealth." International Journal of Research in Pharmaceutical Sciences 11, no. Special Issue 1 (2020): 455-61. https://doi.org/10.26452/ijrps.v11iSP $\underline{\mathrm{L} 1.2811 .}$.

[22] Chawla, D., P. Wagh, S. Ali, U. Jadhav, and B. Ghewade. "Impact of COVID 19 Pandemic on Tuerculosis." International Journal of Research in Pharmaceutical Sciences 11, no. Special Issue 1 (2020): 108488.

https://doi.org/10.26452/ijrps.v11iSP L1.3533.

[23] Jachak, S., P. Phansopkar, and M. Waqar Naqvi. "Impact of Covid-19 in India, a Disastrous Pandemic Outbreak." International Journal of Research in Pharmaceutical Sciences 11, no. Special Issue 1 (2020): 399402.

https://doi.org/10.26452/ijrps.v11iSP L1.2735.

[24] Mujbaile, N.S., and S. Damke. "The Impact of COVID 19 on Pregnant Women and Child Health." International Journal of Research in Pharmaceutical Sciences 11, no. Special Issue 1 (2020): 1367-73. https://doi.org/10.26452/ijrps.v11iSP L1.3645.

[25] Patil, D., and W.M. Naqvi. "COVID19 and Education System: Impact of Current Pandemic on Adaptive Learning Strategies in Medical Education System." International Journal of Research in Pharmaceutical Sciences 11, no. Special Issue 1 (2020): 403-6. https://doi.org/10.26452/ijrps.v11iSP L1.2736.

[26] Sahu, A., and W.M. Naqvi. "Floating Countries and Corona Pandemic: Impact of Covid-19 on Stranded
Cruise Ships." International Journal of Research in Pharmaceutical Sciences 11, no. Special Issue 1 (2020): 219-23. https://doi.org/10.26452/ijrps.v11iSP L1.2702.

[27] Anjankar, V.P., A.P. Anjankar, and A.J. Anjankar. "Review of the Impact of COVID-19 on Medical Education System." International Journal of Current Research and Review 12, no. 20 (2020): 183-86. https://doi.org/10.31782/IJCRR.2020 .122025 . 